\title{
Conference Modern Electrochemical Methods XXXVI, Czech Republic, 2016
}

\author{
Tomáš Navrátil ${ }^{1}$ (D) $\cdot$ Miroslav Fojta $^{2}$
}

Received: 1 February 2017/Accepted: 2 February 2017/Published online: 22 February 2017

(c) Springer-Verlag Wien 2017

This Special Issue of Monatshefte fur Chemie-Chemical Monthly is dedicated to lectures presented at an international conference, which took place in May 2016 in the Czech Republic: Modern Electrochemical Methods XXXVI (MEM; May 23-27, 2016, in Jetrichovice, Czech Republic). This meeting belongs to the traditional series of conferences started in 1980 in Mezni Louka, Czech Republic. It is our great pleasure to introduce this third special issue of the journal Monatshefte fur ChemieChemical Monthly, devoted to the MEM series (in addition to MEM XXXIV and MEM XXXV which were organized in 2014 and 2015, respectively). Yet in the Editorials of the previous special issues, we expressed our belief that this is the start of a new, long and strong tradition.

MEM conferences have been organized annually since 1980 (with only one exception in 1989). Particular events of this series were held at various places of the Czech Republic. However, Jetrichovice near Decin ("Bohemian Switzerland" region in the west-northern part of the Czech Republic) has become the favorite venue among regular MEM participants and the last 17 years of the MEM conferences were organized almost exclusively there (with only two exceptions in 2001 and 2002).

We are very pleased that this conference has become an attractive platform for young as well as top experienced senior (not only electroanalytical) chemists. The numbers

Tomáš Navráti

Tomas.Navratil@jh-inst.cas.cz

1 J. Heyrovský Institute of Physical Chemistry of the CAS, v.v.i., Dolejškova 3, 18200 Prague 8, Czech Republic

2 Institute of Biophysics of the CAS, v.v.i., Kralovopolská 135, 61265 Brno, Czech Republic of participants and presented lectures have been increasing year by year impressively (from six lectures in 1980 to almost 70 lectures in 2016). At the beginning, only the chemists from former Czechoslovakia took part, while in recent years, we had the pleasure to welcome participants from many European (Russia, Germany, Slovenia, Romania, Great Britain) as well as from non-European countries (e.g., USA, India, Iran, Egypt, and the Republic of South Africa). At present, the MEM conferences belong to ISEsponsored events and the conference Proceedings have been indexed in Conference Proceedings Citation Index lists of "Web of Science" since 2010. The growing number of researchers participating at the MEM conferences is mirrored in increasing quality of the presentations. It is only a pity that the number of participants from industry and practical laboratories is still rather low.

Similarly as in the previous years, in 2016, the presented lectures were devoted to progress in electrochemistry of organic and bioactive compounds, to studies of mechanisms of electrochemical processes involving reducible or oxidizable organic species, to development of novel materials for construction of working electrodes, design of measuring configurations and electrochemical (bio)sensors, as well as to analytical techniques designed for the determination of biologically active compounds (such as toxic substances or drugs) in various matrices. Attention was also paid to electrochemical analysis of biopolymers, to their labeling with redox-active species and prospective utilization in novel diagnostic approaches employing electrochemical detection platforms. Moreover, some contributions dealt with utilization of some other analytical techniques, e.g., mass spectrometry, HPLC, and their combinations with electrochemical techniques.

This issue contains 25 original papers derived from lectures presented at the MEM XXXVI. These articles 
comprise a representative selection of contributions covering the above topics.

As Editors of this special issue, we would like to express our gratitude to the Editor-in-Chief of the journal, Peter Gärtner, and to the Managing Editor, Christian Hametner, for their assistance and cooperation, and the staff of the Publisher, Springer Vienna, for their contribution to the special issue release. We are very glad that it has been enabled to realize the series of three special issues which brought to the readers of the journal Monatshefte fur Chemie-Chemical Monthly information about our conferences and about results and topics presented there.

Again, we thank all authors for their great effort to contribute with the results of their research, and all referees for valuable comments that helped to improve the quality of the manuscripts.

Enjoy reading! 